\title{
Two Helminthic Cases of Human Mummy Remains from Joseon-Period Graves in Korea
}

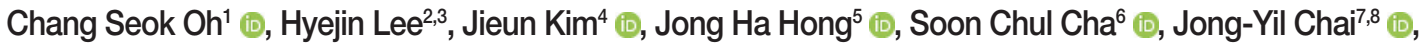

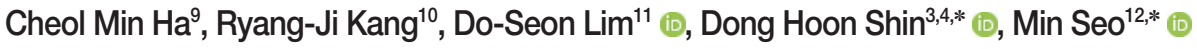

'Department of Mortuary Science, College of Bio-Convergence, Eulji University, Seongnam 13135, Korea; ${ }^{2}$ Ministry of National Defense Agency for KIA Recovery \& Identification, Seoul 06984, Korea; ${ }^{3}$ nnstitute of Forensic and Anthropological Science, Seoul National University College of Medicine,

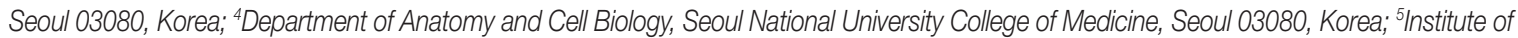
Archaeology and Ancient History, Kyung Hee University, Seoul 02447, Korea; ${ }^{6}$ Seorabeol Institute of Cultural Properties, Gyeongju 38160, Korea;

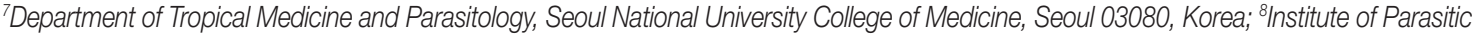
Diseases, Korea Association of Health Promotion, Seoul 07649, Korea; ${ }^{~}$ Hangang Institute of Cultural Heritage, Bucheon 14502, Korea; ${ }^{10} \mathrm{Gaon}$ Research Institute of Cultural Properties, Goryeong 40141, Korea; ${ }^{11}$ Department of Dental Hygiene, College of Health Science, Eulji University, Seongnam 13135, Korea; ${ }^{12}$ Department of Parasitology, Dankook University College of Medicine, Cheonan 31116, Korea
\end{abstract}

\begin{abstract}
Our previous research on coprolite specimens from the mummies of Joseon Dynasty (1392-1910 CE) has revealed various species of parasite eggs. Herein, we added 2 new helminthic cases of human remains from Joseon-period graves in the Republic of Korea (Korea). The organic materials precipitated on the hip bones of 2 half-mummied cases (Goryeong and Gwangmyeong cases) were collected, rehydrated, and examined by a microscope. In the sample from Goryeong-gun (gun=County), ova of Trichuris trichiura, Clonorchis sinensis, and Metagonimus spp. were detected, and eggs of $T$. trichiura and A. lumbricoides were found from the sample of Gwangmyeong-si (si=City). By adding this outcome to the existing data pool, we confirm our previous estimates of Joseon-period parasite infection rates. The overall rates of $A$. lumbricoides, $T$. trichiura, and $C$. sinensis decreased dramatically from Joseon to the modern period. In Goryeong mummy specimen, we also found Metagonimus spp. eggs that has rarely been detected in archaeological samples so far.
\end{abstract}

Key words: Clonorchis sinensis, Ascaris lumbricoides, Trichuris trichiura, history, mummy, archaeoparasitology, Korea

\section{INTRODUCTION}

Over the past decades, archaeoparasitology has successfully reconstructed historical Korean parasite-infection prevalence. Especially, through research on parasite eggs found in Joseonperiod mummies, parasitologists have revealed infection patterns and their changes over time. In our previous studies, more than 10 species of helminth eggs and larvae, i.e., Ascaris lumbricoides, Trichuris trichiura, Enterobius vermicularis, Strongyloides sp., Trichostrongylus orientalis, Clonorchis, sinensis, Paragonimus westermani, Metagonimus spp., Gymnophalloides seoi and Taenia spp., were detected from the grave samples of Joseonperiod mummies. These contents are summarized in 2 review

- Received 14 December 2020, revised 10 March 2021, accepted 25 March 2021.

*Corresponding authors (cuteminjae@gmail.com; bbbenjj@naver.com)

(c) 2021, Korean Society for Parasitology and Tropical Medicine

This is an Open Access article distributed under the terms of the Creative Commons

Attribution Non-Commercial License (https://creativecommons.org/icenses/by-nc/4.0

which permits unrestricted non-commercial use, distribution, and reproduction in any

medium, provided the original work is properly cited. papers in detail $[1,2]$.

Notwithstanding this wealth of scientific data, drawing definitive conclusions on the parasite infection status of our Joseon-period ancestors requires additional archaeoparasitological reports representative of much wider temporal and geographical strata [2]. Many archaeological excavations are carried out for Joseon period graves throughout the country; and during the investigations, well-preserved mummies have been discovered every year and parasitic examinations have been commissioned. Continuous parasitological research on Korean mummy specimens is thus essential to reveal parasite infection in history pattern more accurately and precisely. Herein then, we report novel parasitological data derived from recently investigated Joseon-period mummies. Consideration of these cases in conjunction with previous reports enabled us to more clearly understand the pattern of parasitism prevailing among Koreans of Joseon Dynasty period. 


\section{CASE DESCRIPTION}

Archaeologists discovered the graves at Goryeong-gun (gun= County), Gyeongsangbuk-do (do=Province) $\left(35^{\circ} 44^{\prime} 38.9^{\prime \prime} \mathrm{N}, 128^{\circ}\right.$ $\left.16^{\prime} 08.4^{\prime \prime} \mathrm{E}\right)$, and Gwangmyeong-si (si =City), Gyeonggi-do (37 $\left.26^{\prime} 52.0^{\prime \prime} \mathrm{N}, 126^{\circ} 51^{\prime} 07.0^{\prime \prime} \mathrm{E}\right)$, respectively. Judging from the clothing and grave type, archaeologists confirmed that these graves were constructed during Joseon period [3-5]. As for the Goryeong case, the Joseon grave was investigated by the Gaon Research Institute of Cultural Properties (Goryeong-gun, Korea). The grave of the Gwangmyeong case was examined by the Hangang Institute of Cultural Heritage (Seoul, Korea). The half-mummified remain was moved to a lab at the Department of Mortuary Science, College of Bio-convergence, Eulji University (Seongnam-si, Korea).

The parasitological specimens in these cases were obtained from the hip bones (Fig. 1). The organic materials precipitated on the hip bone were treated for parasitological examination. Specimens ranging in weight from 1 to $4 \mathrm{~g}$ were re-hydrated in trisodium phosphate buffered (0.5\%) solution [6-8], filtered through gauze, and precipitated for a day. Then, the precipitates were re-dissolved in the same buffered solution $(20 \mathrm{ml})$. The solution was dropped onto slides; and then prepared slides ( $20 \mu \mathrm{l}$ for each; total $200 \mu \mathrm{l}$ ) were examined by a light-
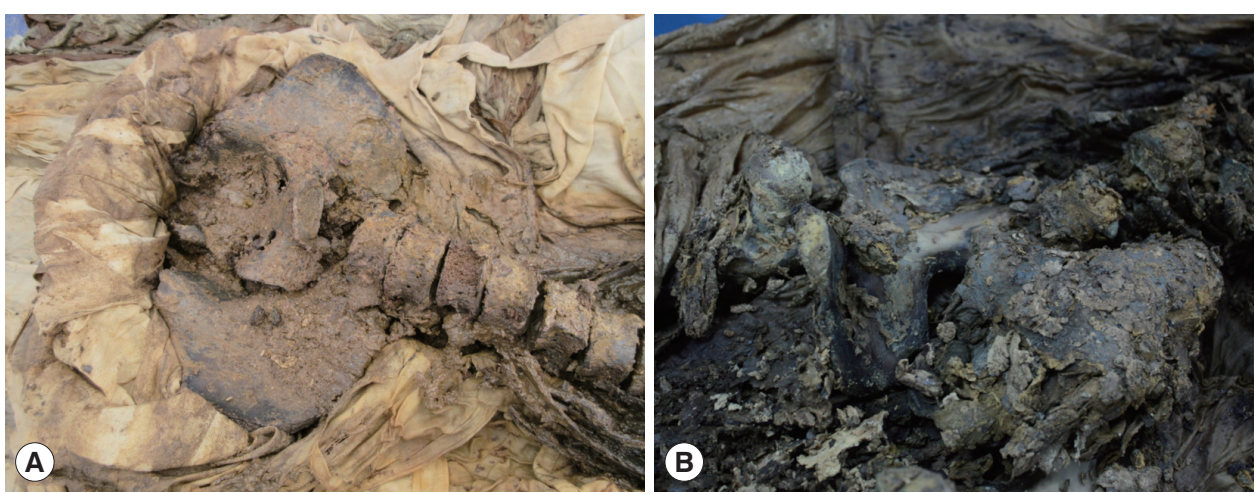

Fig. 1. Organic materials precipitated on the pelvic regions of 2 human remains examined in this study. (A) Goryeong-gun (gun= County) and (B) Gwangmyeong-si (si = City) cases.
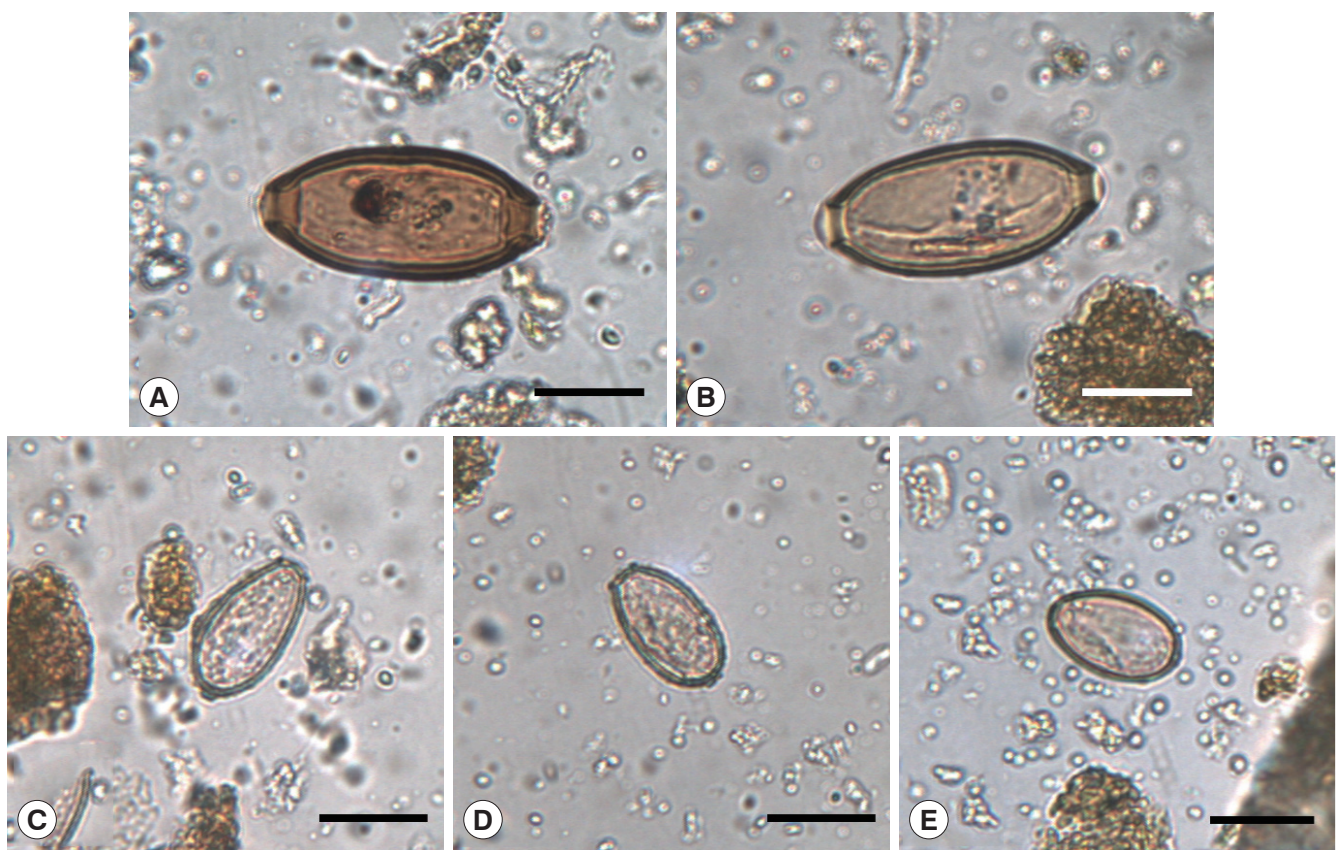

Fig. 2. Ancient parasite eggs found in Goryeong-gun (gun=County) case. (A, B) Trichuris trichiura eggs, (C, D) Clonorchis sinensis eggs, (E) Metagonimus sp. egg. Scale bar $=20 \mu \mathrm{m}$. 


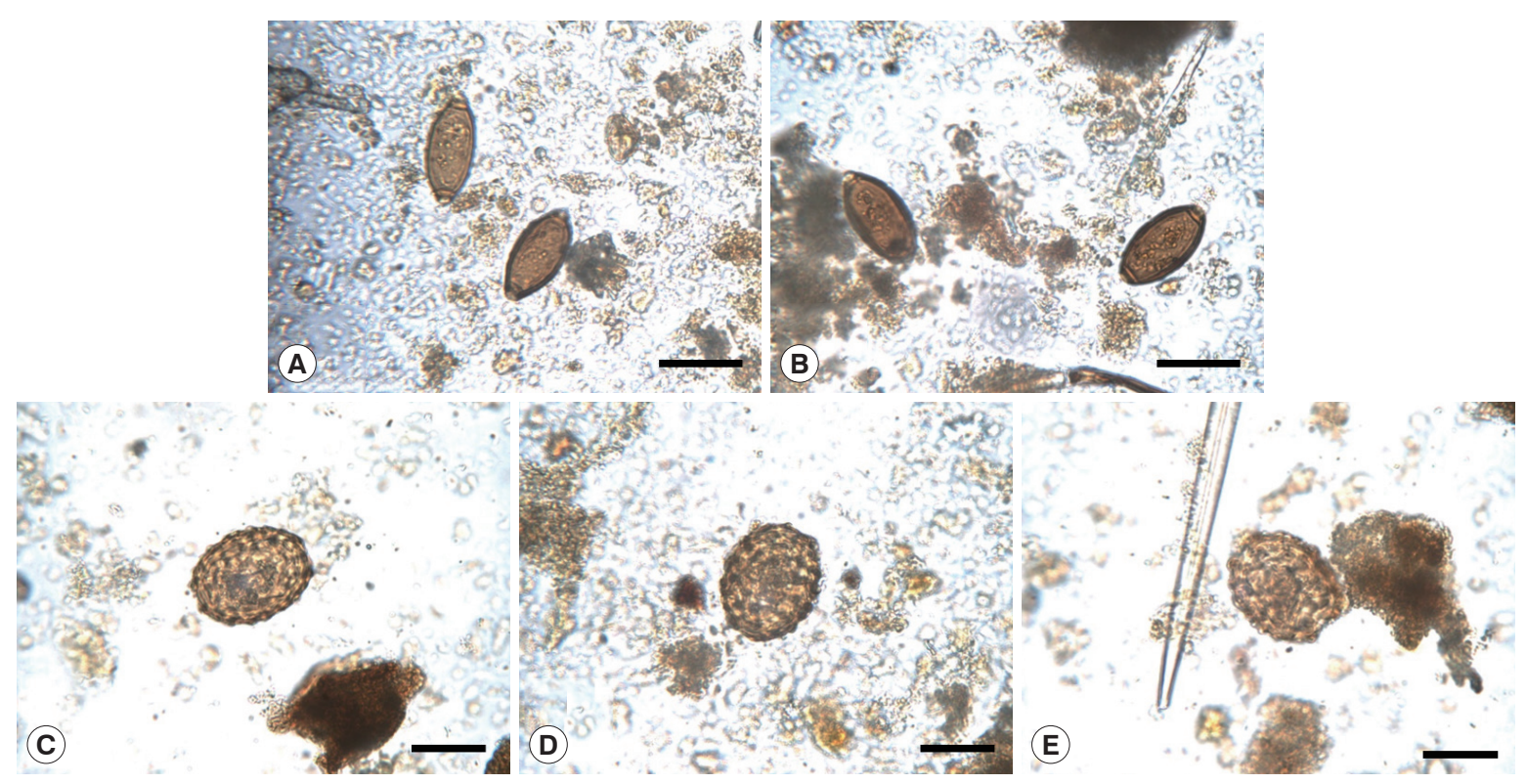

Fig. 3. Ancient parasite eggs found in Gwangmyeong-si (si=City) case. (A, B) Trichuris trichiura eggs, (C-E) Ascaris lumbricoides eggs. Scale bar $=40 \mu \mathrm{m}$.

Table 1. Size of helminth eggs and number of eggs per a gram of feces obtained in this study

\begin{tabular}{llcc}
\hline \multirow{2}{*}{ Mummy case } & Parasite eggs discovered & Egg size $(\mu \mathrm{m})$ & Eggs per gram of feces \\
\cline { 3 - 4 } Goryeong & T. trichiura & Length $\times$ Width & 6017 \\
& C. sinensis & $55.0 \pm 0.0 \times 28.3 \pm 2.9$ & 19207 \\
Gwangmyeong & Metagonimus spp. ${ }^{a}$ & $30.3 \pm 1.0 \times 15.7 \pm 0.6$ & $\mathrm{NM}^{b}$ \\
& T. trichiura & $27.5 \pm 0.0 \times 16.25 \pm 1.2$ & 3744 \\
\hline
\end{tabular}

a2 eggs, bNM: Not measured.

microscope (BH-2; Olympus, Tokyo, Japan). The parasite eggs' size was measured, and the eggs per gram of feces was also estimated as described by Seo et al. [2].

In the sample from Goryeong-gun, numerous eggs of $T$. trichiura (Fig. 2A, B) and C. sinensis (Fig. 2C, D) were detected, but only 2 eggs of Metagonimus spp. (Fig. 2E) were found. In the sample from Gwangmyeong-si, ova of T. trichiura (Fig. 3A, B) and A. lumbricoides (Fig. 3C-E) were detected. The size of helminth eggs detected and the number of eggs per a gram of feces (EPG) were designated in Table 1 in detail.

\section{DISCUSSION}

For the past decades, we have estimated Joseon parasite infection rates based on the study of mummy coprolite specimens. Until the present study, the number of mummy cases utilized in this way was 24 [2]. In this report, we added the data of 2 Korean mummies to the existing data pool of ancient parasite eggs. The areas surveyed in this study (Goryeong-gun and Gwangmyeong-si) are the ones where there have been no reports of ancient parasites from the Joseon Dynasty mummies.

Current report showed that the Joseon A. lumbricoides and T. trichiura infection rates are $57.7 \%$ (15/26) and 84.6\% (22/26), respectively. In 1971 national survey data [9], the infection rates of A. lumbricoides and T. trichiura were 54.9 and $65.4 \%$, respectively. In the case of $C$. sinensis, the eggs were found in $26.9 \%(7 / 26)$ of the Joseon mummies. This is much higher than the $4.6 \%$ infection rate of C.sinensis in the 1971 national survey $[2,9]$. As seen in our previous studies $[2,10]$, we found that the overall rates of A. lumbricoides, T. trichiura, and C. sinensis decreased dramatically from Joseon to the modern period. We also note that Goryeong mummy is the 4th Joseon case to show Metagonimus spp. infection. The previous mum- 
my cases of Metagonimus spp. infection were discovered at Sapgyo-eup (eup = town), Hadong-gun, and Sacheon-si in Korea [11]. Since ancient Metagonimus spp. eggs has rarely been detected in archaeological samples, this finding is meaningful to archaeoparasitologists.

Despite the achievements in our report, we cannot help but admit that there is still a technical limit to this study. For instance, the reported number of Joseon mummies is increasing every year, but it is still difficult to say that enough parasitic investigations have been conducted on them. In addition, molecular biological analysis has not been performed on ancient parasite eggs in this report, which we hope to take other opportunities to try.

\section{ACKNOWLEDGMENT}

This research was supported by Basic Science Research Program through the National Research Foundation of Korea by the Ministry of Science and ICT (2020R1A2C1010708).

\section{CONFLICT OF INTEREST}

All authors declare no conflict of interest.

\section{REFERENCES}

1. Seo M, Araujo A, Reinhard K, Chai JY, Shin DH. Paleoparasitological studies on mummies of the Joseon dynasty, Korea. Korean J Parasitol 2014; 52: 235-242. https://doi.org/10.3347/kjp.2014.52.3.235

2. Seo M, Oh CS, Hong JH, Chai JY, Cha SC, Bang Y, Cha IG, Wi YG, Park JM, Shin DH. Estimation of parasite infection prevalence of Joseon people by paleoparasitological data updates from the ancient feces of pre-modern Korean mummies. Anthropol Sci 2017; 125: 9-14. https://doi.org/10.1537/ase.160920

3. Song MK. Study on the characteristics of each period to identify the women's costume of the Joseon Dynasty - based on the excavated costumes from 15th to 18th century. J Korean Soc Costume 2008; 58: 71-86 (in Korean).

4. Song MK. Estimation of historical dates of the clothes excavated from “Euiin”-Park’s tomb. J Korean Soc Costume 2009; 59: 135151 (in Korean).

5. Lee EJ, Oh CS, Yim SG, Park JB, Kim YS, Shin MH, Lee SD, Shin DH. Collaboration of archaeologists, historians and bioarchaeologists during removal of clothing from Korean mummy of Joseon dynasty. Int J Hist Archaeol 2013; 17: 94-118. https://doi.org/10.1007/ s10761-012-0211-0

6. Van Cleave HJ. Ross JA. A method for reclaiming dried zoological specimens. Science 1947; 105: 318. https://doi.org/10.1126/ science.105.2725.318

7. Han ET, Guk SM, Kim JL, Jeong HJ, Kim SN, Chai JY. Detection of parasite eggs from archaeological excavations in the Republic of Korea. Mem Inst Oswaldo Cruz 2003; 98: 123-126. https:// doi.org/10.1590/s0074-02762003000900018

8. Reinhard K, Urban O. Diagnosing ancient diphyllobothriasis from Chinchorro mummies. Mem Inst Oswaldo Cruz 2003; 98: 191-193. https://doi.org/10.1590/S0074-02762003000900028

9. Korea Centers for Disease Control and Prevention. Korea Association of Health Promotion: Prevalence of Intestinal Parasitic Infections in Korea. The 8th Report. Seoul, Korea. Art Motion. 2012. http:// www.bokjiro.go.kr/cmm/fms/FileDown.do?atchFileId=6013284

10. Seo M, Hong JH, Reinhard K, Shin DH. Archaeoparasitology of Korean mummies. In Shin DH, Bianucci R eds, The Handbook of Mummy Studies. Singapore. Springer. 2020, pp 1-21. https:// doi.org/10.1007/978-981-15-1614-6

11. Hong JH, Seo M, Oh CS, Chai JY, Shin DH. Metagonimus yokogawai ancient DNA recovered from 16th- to 17th-century Korean mummy feces of the Joseon Dynasty. J Parasitol 2020; 106: 802808. https://doi.org/10.1645/20-42 